\title{
COMMENTARY
}

\section{The question of repeat biopsies}

\author{
Jehonathan H. Pinthus, MD, PhD
}

See related article on page 245

T he paper by Amin and colleagues ${ }^{1}$ confirms previous reports that show that in the era of extended transrectal ultrasound (TRUS) guided prostate biopsy, a finding of atypical small acinar proliferation (ASAP) in the initial biopsy is a strong predictor for a subsequent finding of prostate cancer in repeat biopsies; whereas, the finding of high-grade intraepithelial neoplasia (HGPIN) has no additional predictability for finding prostate cancer on repeat biopsies. The reason for the high rates of subsequent detection of prostate cancer in patients with findings of ASAP on initial TRUS-guided biopsy probably stems from the fact that ASAP denotes an area with findings suggestive but not diagnostic of carcinoma. Indeed, when another experienced pathologist subjects these cases to re-evaluation, more than one-half will be confirmed as cancer. ${ }^{2}$ Performing a repeat TRUS-guided biopsy, though, will be very helpful in obtaining additional prognostic data such as Gleason score (which has been recorded in this study to be as high as 8), number of cores involved, percentage of core involvement and location.

Although it is clear from this study and many others that a finding of HGPIN on initial extended TRUS-guided biopsy does not imply any greater risk for a subsequent finding of cancer on repeat biopsies (compared with patients who had initial normal extended TRUS-guided biopsy), it seems that the risk is still high enough $(21.9 \%$, i.e., almost 1 in 4 patients) to justify the performance of a repeat extended TRUS-guided biopsy soon after the initial one. The authors' suggestion to triage these cases to immediate or delay re-biopsy according to clinical parameters such as prostate specific antigen density is appealing but should be confirmed prospectively on a larger cohort of patients in whom an extended initial TRUS-guided biopsy is the standard of care.

From the Department of Surgery, Division of Urology, McMaster University, Hamilton, Ont.

Competing interests: None declared.

\section{References}

1. Amin MM, Jeyaganth S, Fahmy N, et al. Subsequent prostate cancer detection in patients with prostatic intraepithelial neoplasia or atypical small acinar proliferation. CUAJ 2007; 1:245-9

2. Chan TY, Epstein Jl. Patient and urologist driven second opinion of prostate needle biopsies. J Urol 2005;174:1390-4.

Correspondence: Dr. Jehonathan H. Pinthus, Juravinski Cancer Center, 699 Concession St., Hamilton ON L8V JC2; Jehonathan.Pinthus@hrcc.on.ca 